\title{
Neurolytic block of ganglion of Walther for the management of chronic pelvic pain
}

\author{
Małgorzata Malec-Milewska1 , Bartosz Horosz ${ }^{1}$, Iwona Kolęda², Agnieszka Sękowska², Hanna Kucia², \\ Dariusz Kosson ${ }^{1,3}$, Grzegorz Jakiel ${ }^{4}$ \\ ${ }^{1}$ Department of Anesthesiology and Intensive Care, Medical Center for Postgraduate Education, Warsaw, Poland \\ 2Pain Clinic, Department of Anesthesiology and Intensive Care, Medical Center for Postgraduate Education, Warsaw, Poland \\ ${ }^{3} 1^{\text {st }}$ Department of Anesthesiology and Intensive Care, Warsaw Medical University, Warsaw, Poland \\ ${ }^{4} 1^{\text {st }}$ Department of Obstetrics and Gynecology, Medical Center for Postgraduate Education, Warsaw, Poland
}

Videosurgery Miniinv 2014; 9 (3): 458-462 DOI: $10.5114 /$ wiitm.2014.43079

\begin{abstract}
Here we report on the use of neurolytic block of ganglion impar (ganglion of Walther) for the management of intractable chronic pelvic pain, which is common enough to be recognized as a problem by gynecologists, likely to be difficult to diagnose and even more challenging to manage. Following failure in controlling the symptoms with pharmacological management, nine women underwent neurolysis of the ganglion impar in our Pain Clinic from 2009 to March 2013. The indication for the procedure was chronic pelvic pain (CPP) of either malignancy-related (4) or other origin (5). The Numeric Rating Scale (NRS) and duration of pain relief were employed to assess effectiveness of the procedure. Neurolysis was efficacious in patients with both malignancy-related CPP and CPP of non-malignant origin. Reported relief time varied from 4 weeks to 3 years, while in 4 cases complete and permanent cessation of pain was achieved. No complications were noted.
\end{abstract}

Key words: ganglion impar, ganglion of Walther, neurolytic block, chronic cancer pain, chronic pelvic pain, Numeric Rating Scale.

\section{Introduction}

Chronic pelvic pain (CPP) is a challenge to the treating physician and given its prevalence of $15 \%$ in women aged $18-50$ years it is likely to be encountered in gynecological practice [1]. Pelvic pain may result in substantial functional impairment, while its socio-cultural effects are known to be paramount [2]. Studies investigating the prevalence and pathophysiology of this condition focus on various groups of patients, hence the broad pattern of reported etiology, which in a large proportion of subjects is not possible to identify. Women with CPP exert clinical symptoms directing the diagnostic process towards either gastrointestinal, urinary or gynecological problems, of which reproductive system pathology may be found in up to $20 \%$ of cases $[2,3]$. Its complex origin results in diverse presentation: sympathetically mediated pain is experienced as dull, burning, poorly localized pain, while sharp, shooting and lancinating character is suggestive of somatic etiology. Thus thorough medical history aided by physical examination is usually sufficient to differentiate pain nature. A routine approach to chronic pain management is applicable in CPP management, with the use of psychotherapy, titrated analgesics, adjuvant antidepressants and anticonvulsants. Failure to control symptoms with pharmacological management

\section{Address for correspondence}

Małgorzata Malec-Milewska MD, PhD, Department of Anesthesiology and Intensive Care, Medical Center for Postgraduate Education,

231 Czerniakowska St, 00-416 Warsaw, Poland, phone: +48 2258412 20, e-mail: Imilewski@post.pl 
calls for invasive techniques to be employed, such as surgical presacral neurectomy or laparoscopic utero-sacral nerve ablation [4]. Although not very popular, interventional pain management procedures are also highly effective in CPP, including cases of specifically gynecological origin. The ganglion impar (also known as the ganglion of Walther) is a solitary anatomical feature, found on the ventral surface of the coccyx, at the level of the sacro-coccygeal joint, where it forms the caudal origin of the bilateral sympathetic chain. It provides sympathetic innervation to the perineal and anal area. Neurolytic block of the ganglion impar, producing prolonged disruption of afferent sympathetic and nociceptive routes from the pelvis and perineal/ anal area, is effectively used in otherwise difficult cases with a highly desirable risk-to-benefit ratio. It helps the patients to get back to their normal functioning once the leading disease is resolved or helps to keep pain at bay for those who have lost their battle against cancer.

\section{Case reports}

In the Pain Clinic of the Department of Anesthesiology and Intensive Care, Medical Center of Post- graduate Education in Warsaw, from 2009 to May 2013 neurolysis of ganglion impar was proposed and performed in 9 female patients with CPP, aged from 43 to 73 years. Their demographics are given in Table I. All of them had suffered from CPP and failed to respond sufficiently to optimized pharmacologic management. A total of 16 neurolytic procedures were performed. Neurolytic blocks were performed in the operating theatre, with the use of C-arm fluoroscopic guidance. Patients were all considered outpatients; none of them was admitted as an inpatient. In all cases the prognostic block was done (with local anesthetic, steroid and pentoxifylline) and the decision to proceed with neurolysis depended on its beneficial effect. A follow-up visit after a month, when the first assessment of the therapeutic result was recorded, was routine.

\section{Technique}

First described by Plancarte et al. [5], the block technique has been extensively modified and it appears that now the most common approach used to reach the ganglion is the direct route via the sacrococcygeal joint, when 4-6 $\mathrm{ml}$ of neurolytic agent is injected af-

Table I. Demographics and clinical data of cases presented

\begin{tabular}{|c|c|c|c|c|c|}
\hline No. & Age & Past medical history & Area affected & $\begin{array}{l}\text { Symptoms } \\
\text { duration } \\
\text { [years] }\end{array}$ & $\begin{array}{l}\text { Pain Clinic treatment } \\
\text { introduced prior to neurolytic } \\
\text { block }\end{array}$ \\
\hline 1 & 73 & $\begin{array}{c}\text { Hemorrhoidectomy, perineal recon- } \\
\text { struction, vaginal dryness }\end{array}$ & Anal and perineal area & 5 & $\begin{array}{l}\text { Gabapentin, amitriptyline } \\
\text { folic acid }\end{array}$ \\
\hline 2 & 77 & $\begin{array}{l}\text { Chronic cystitis, HT, } \\
\text { urinary incontinence }\end{array}$ & Perineal and pelvic pain & 8 & Oxybutynin, citalopram \\
\hline 3 & 53 & Myomectomy, ileus, LBP & Perineal and pelvic pain & 6 & Mianserin, sertraline \\
\hline 4 & 62 & $\begin{array}{l}\text { Cervical cancer with subsequent } \\
\text { radio- and chemotherapy, current } \\
\text { inoperable vaginal cancer }\end{array}$ & Perineal & 5 & Slow-release morphine \\
\hline 5 & 59 & Anterior resection due to cancer & Perineal and anal & 4 & $\begin{array}{c}\text { Fentanyl patches, oxycodone, } \\
\text { amitriptyline }\end{array}$ \\
\hline 6 & 65 & $\begin{array}{c}\text { Abdominoperineal resection, } \\
\text { radiotherapy }\end{array}$ & $\begin{array}{l}\text { Perineal and phantom } \\
\text { pain }\end{array}$ & 1 & Slow-release tramadol \\
\hline 7 & 58 & $\begin{array}{c}\text { Metastatic adenocarcinoma of } \\
\text { Bartholin's gland. Multiple surgical } \\
\text { procedures }\end{array}$ & Perineal & 7 & $\begin{array}{c}\text { Fentanyl patches, amitriptyline, } \\
\text { gabapentin }\end{array}$ \\
\hline 8 & 72 & $\begin{array}{c}\text { HT, degenerative disease of the L-S } \\
\text { spine, bilateral THR }\end{array}$ & Perineal & 5 & $\begin{array}{l}\text { Buprenorphine patches, tetraze- } \\
\text { pam, sertraline }\end{array}$ \\
\hline 9 & 43 & TAH, THR, LBP & Anal, perineal & 3 & $\begin{array}{l}\text { Buprenorphine patches, } \\
\text { venlafaxine, trazodone }\end{array}$ \\
\hline
\end{tabular}




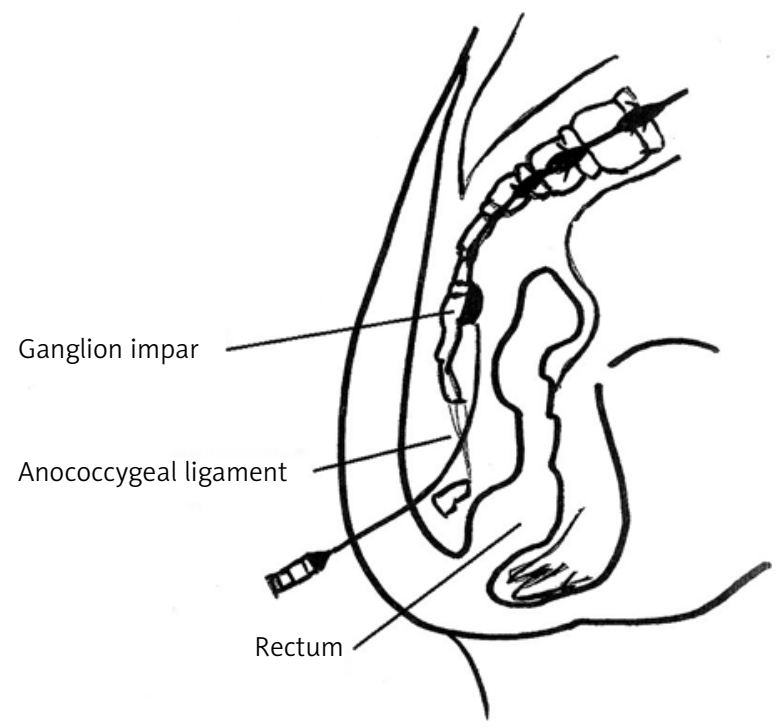

Figure 1. Anatomy and block technique

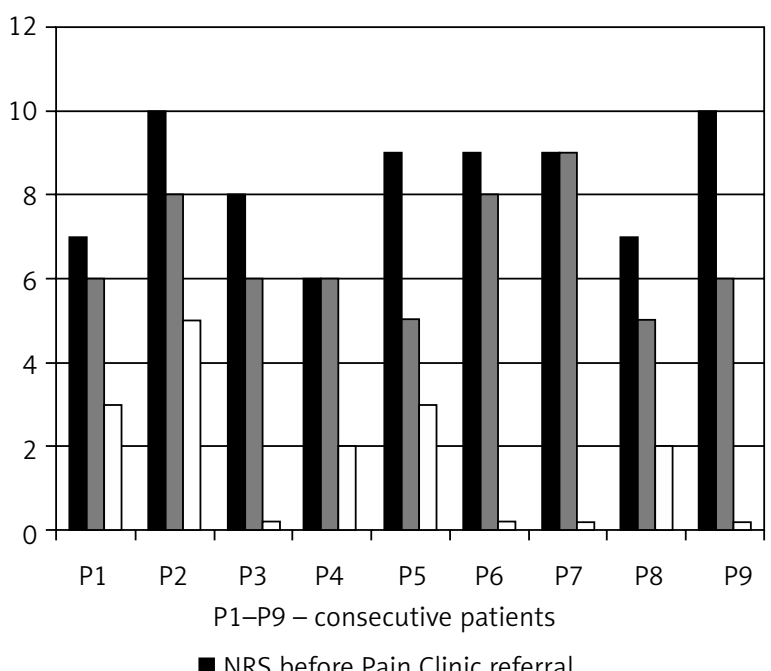

$\square$ NRS after pharmacological management was optimized $\square$ NRS 1 month after the $1^{\text {st }}$ neurolytic block

Figure 2. Results of pharmacological treatment and neurolytic block

ter the fluoroscopic confirmation of accurate needle placement [6]. Due to close proximity of the rectum, its inadvertent puncture is an obvious hazard. In our center we use a different approach, with a curved $22 \mathrm{G}$ spinal needle introduced through the anococcygeal ligament and advanced under fluoroscopic guidance to reach the ventral surface of the sacrococcygeal joint, as described by Nebab and Florence [7].

The procedure is performed with the patient positioned in the left decubitus position. Anatomy

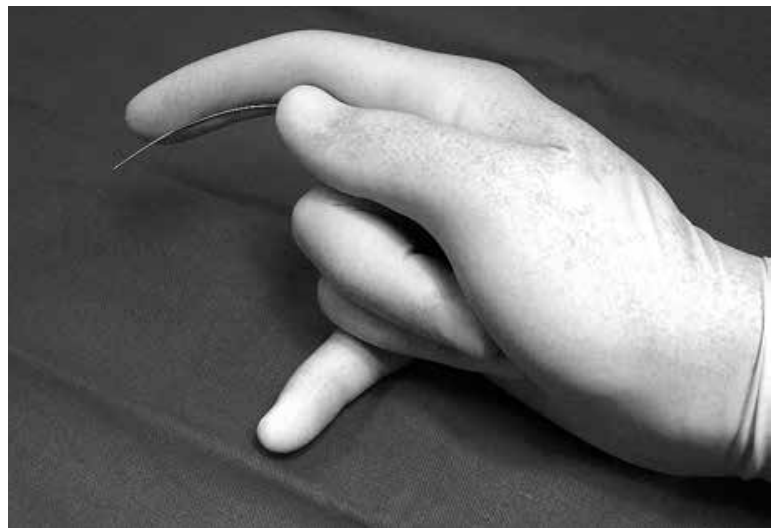

Photo 1. Needle position in the hand

and route of needle insertion are shown in Figure 1. A 22 gauge spinal needle (Quincke) is reshaped to reflect the curvature of an arc (Photo 1). After the skin infiltration with $1 \%$ lidocaine at the site of needle entry, the needle is passed through the anococcygeal ligament onto the anterior surface of the coccyx and advanced cephalad under fluoroscopic guidance until its tip reaches the level of the sacrococcygeal joint. The curvature of the needle allows for easy advancement with minimal tissue damage and patient discomfort. Curved as described, it comfortably fits into the operator's hand and the tip may be easily manipulated with just one or two fingers.

After the desired position is reached, it is confirmed by contrast injection, which should spread evenly in a linear manner just anterior of the sacrococcygeal joint. A neurolytic agent is then injected, $4-6 \mathrm{ml}$ of $65 \%$ alcohol with lidocaine.

If the coccyx is extensively bent or otherwise damaged, then a lateral approach is used, inserting the needle just lateral of the sacrococcygeal joint and directing it onto its ventral surface. This maneuver is similar to one described by Huang [8], although the needle is inserted above the transverse process of the coccyx, at the level of the sacrococcygeal junction, and directed more caudally. Thanks to its curved shape, the needle position in the hand is firm and ensures that navigating the tip is relatively straightforward; thus placing the finger in the anus to minimize the risk of its inadvertent puncture is not necessary.

\section{Results}

Nine patients consented to neurolysis; in 3 cases the treatment was limited to 1 procedure only. 
A total of 16 neurolytic blocks were completed in these patients and no significant complications were noted. In all CPP patients the reduction in NRS score was clinically significant, which is shown in Figure 2.

Apart from a decrease in constant pain, shooting pain episodes in the majority of cases - which were as severe as 10 on the NRS - largely disappeared. One patient failed to return to the Pain Clinic for follow-up, while at the time of her last contact 10 days after the block she reported no chronic pain or paroxysmal pain episodes (patient no. 6). Seven patients were keen to have the neurolysis repeated, which provided long-lasting (considered permanent) improvement in 4 of them, while one of the patients had 2 more procedures done subsequently, with relief time of nearly 12 months between them. None described procedure-related discomfort as significant. Other CPP patients treated experienced either no improvement after 2 blocks (1 patient), moderate symptoms relief (no noticeable change in constant, but major improvement in paroxysmal pain -1 patient) or died due to the progression of metastatic cancer disease (2 patients). In the latter case procedures performed provided sufficient pain control until their death.

\section{Discussion}

Due to its complex origin, chronic pelvic pain is a challenge to most clinicians, including pain specialists. It is defined as "non-cyclic pain of 6 or more months' duration that localizes to the anatomic pelvis, anterior abdominal wall at or below the umbilicus, the lumbosacral back, or the buttocks, and is of sufficient severity to cause functional disability or lead to medical care" [9]. In a large proportion of CPP cases somatic pain is accompanied by features of neuropathic and/or psychogenic pain. Involvement of other than peripheral nociception mechanisms is advocated by studies which failed to find an evident correlation between pain severity and extent of peripheral tissue damage, e.g. endometriosis [3]. Moreover, women with CPP have been shown to present with decreased grey matter volume in the area of the central nervous system responsible for central nociception regardless of the presence of endometriosis or other identifiable pathology, which is indicative of central sensitization [10]. Failure to control the symptoms with multimodal pharmacological pain management calls for invasive techniques to be employed, of which neurolytic block of the ganglion of Walther was first described by Plancarte et al. in 1990 [5] and found to be effective. Pain of the perineal and anal region is a common feature of CPP in cases where the malignant process originates from the pelvis. Of special interest is phantom pain that affects up to $18 \%$ of patients after pelvic tumor resections, is usually severe, of lancinating, burning, pulsating, crushing and/or stinging character, and has a deleterious effect on patients' daily functioning. The CPP affects both men (prostatitis, coccydynia), and up to $14 \%$ of women (coccydynia, vulvodynia, perineal nerve neuralgia, endometriosis, cystitis) and puts a great burden on public health and healthcare costs [1]. The procedure described in this report has the potential to provide long-lasting or even permanent pain relief. The fact that 7 patients were keen to have the procedure repeated (at least once) is indicative of its clinical potential. A multitude of modifications of the originally described technique were reported, of which the transsacrococcygeal approach is probably the most common. Although effective, it may be difficult in many patients in whom the sacrococcygeal joint is fused and calcified. Given the average age of pain clinic patients it is likely to be an issue in a large number of our subjects. Hence the original route to reach the ganglion impar through the anococcygeal ligament is in use in our center, and over the years has proven to be effective. Similarly to Nebab and Florence [7], we introduce the curved spinal needle in a rotating fashion to avoid excessive tissue damage, which could have occurred if the bent needle was used. Fluoroscopic guidance ensures proper needle placement and negligible risk of rectal puncture. The procedure described has been used in our center for more than 10 years with no complications reported, providing highly significant improvement in quality of life by combating the most disturbing symptom of all - pain. Minor procedure as it is, it is characterized by an outcome similar to surgical techniques (disruption of nociceptive routes), but lacks their risks and possible complications. Although to date no reports are available which compare efficacy of surgical and neurolytic procedures, it appears to be sufficiently effective in CPP, especially when perineal and anal area pain is present.

\section{Conclusions}

Neurolysis of the ganglion of Walther using a curved needle introduced through the anococcy- 
geal ligament appears to be sufficiently effective in patients with chronic pelvic pain, with negligible risk of complications and highly favorable risk-to-benefit ratio.

\section{References}

1. Mathias SD, Kuppermann M, Liberman RF, et al. Chronic pelvic pain: prevalence, health-related quality of life, and economic correlates. Obstet Gynecol 1996; 87: 321-7.

2. Howard FM. The role of laparoscopy in the chronic pelvic pain patient. Clin Obstet Gynecol 2003; 46: 749-66.

3. Vercellini P, Trespidi L, De Giorgi O, et al. Endometriosis and pelvic pain: relation to disease stage and localization. Fertil Steril 1996; 65: 299-304

4. Chen FP, Chang SD, Chu KK, Soong YK. Comparison of laparoscopic presacral neurectomy and laparoscopic uterine nerve ablation for primary dysmenorrhea. J Reprod Med 1996; 41: 463-6.

5. Plancarte R, Amescua C, Patt RB, Allende S. Presacral blockade of the ganglion of Walter (ganglion impar). Anesthesiology 1990; 73 (3A): A751.

6. Wemm K, Saberski L. Modified approach to block the ganglion Impar (ganglion of Walther). Reg Anesth 1995; 20: 544-5.

7. Nebab EG, Florence IM. An alternative needle geometry for interruption of the ganglion impar. Anesthesiology 1997; 86: 1213-4.

8. Huang JJ. Another modified approach to the ganglion of Walther block (ganglion of impar). J Clin Anesth 2003; 15: 282-3.

9. ACOG Committee on Practice Bulletins - Gynecology. ACOG Practice Bulletin No. 51. Chronic pelvic pain. Obstet Gynecol 2004; 103: 589-605.

10. As-Sanie S, Harris RE, Napadow V, et al. Changes in regional gray matter volume in women with chronic pelvic pain: a vox el-based morphometry study. Pain 2012; 153: 1006-14.

Received: 5.09.2013, accepted: 23.01.2014 